\title{
A CASE OF LEONTIASIS OSSEA (DIFFUSE OSTEITIC FORM).
}

\author{
BY
}

NORMAN B. CAPON, M.D., M.R.C.P..

Physician, Royal Southern Hospital, Liverpool.

Two forms of leontiasis ossea are described by Lawford Knaggs "i, 7 namely, a creeping periostitic variety, and a diffuse osteitic variety. The latter would appear to be very rare, and for this reason the details of a case recently observed by myself and my colleagues are now recorded.

V. (.., male, aged 14 years. The parents, and five brothers and sisters are all normal. The patient was born at a full-term, normal labour; ' he seemed a normal infant.' When six years of age he fell from the back of a cart and struck his head on the road.

'The present illness began about two years ago, with frontal headache and deformity of the head. There was no vomiting, and no mental changes were noted. Recently, however, there is some evidence of slight moral deterioration (small thefts) ; and he has had a few "fainting" attacks in the morning.

He scems an alert, intelligent and nervous boy. Routine clinical examination shows no abnormality or disease of the trunk or limbs.

The patient's head is deforned (Fig. 1 to 4) especially in the frontal region, and particularly on the left side, where there is considerable protrusion. The left orbit is displaced forwards,

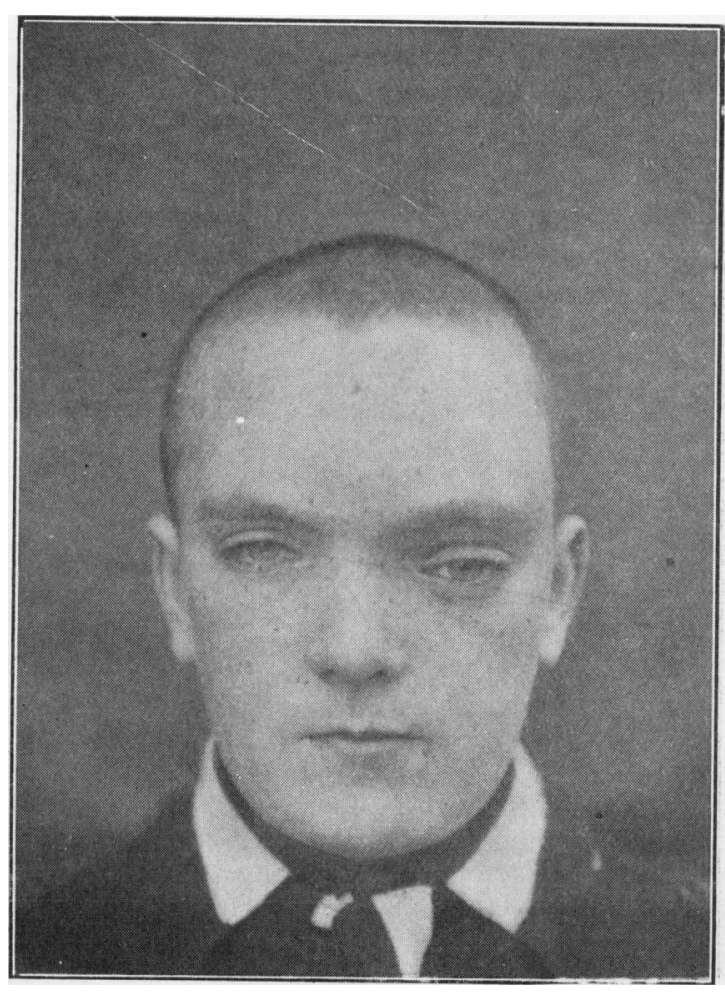

Fin: 1

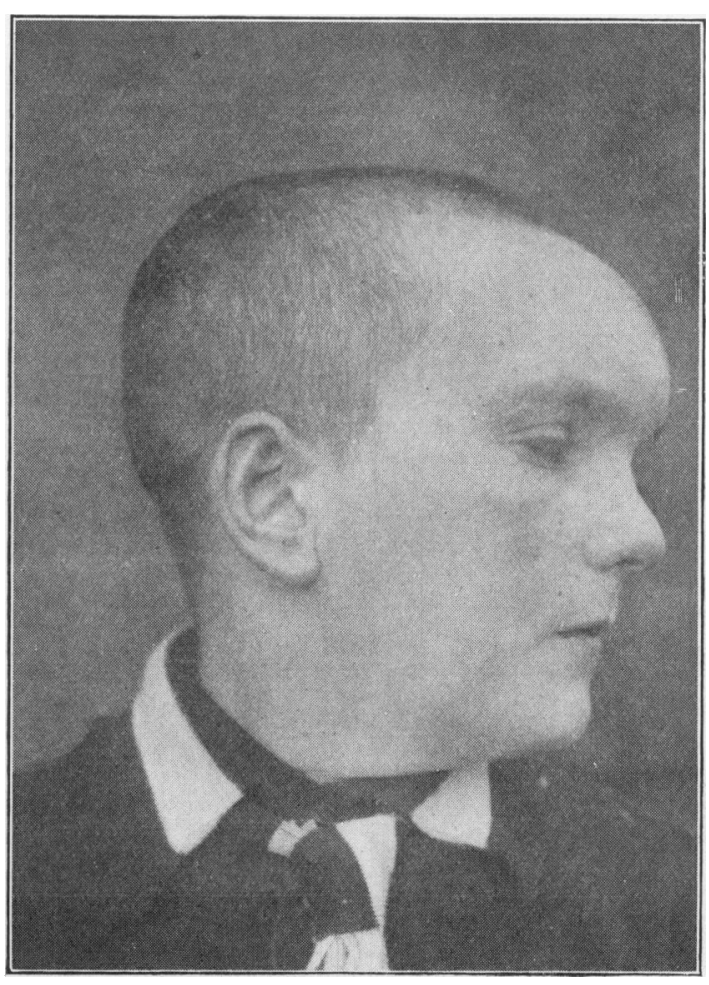

Fli: : 
outwards and downwards; the distance between the inner canthi is $1 \frac{1}{2} \mathrm{in}$. The cranial bones feel uniformly and normally dense ; there is no tenderness, and no change in the skin and subcutaneous tissues overlying the cranium. The maximum occipito-frontal circumference of the head is $22 \frac{3}{8} \mathrm{in}$.

\section{X-Ray Examination. (Dr. J. H. Mather.)}

A. The Skull: lateral view (Fig. 5 and 6). The surface of the skull shows a definite bulge in the frontal region. This is seen to be due to a bony thickening of the frontal bone, most marked in the supraorbital region but also involving the nasal process of the frontal bone and the orbital plate. The thickened bone shows a fairly homogeneous texture, with a few irregular more translucent areas in the diploë. Its contour is smooth. The frontal sinuses are obliterated, and the sagittal diameter of the cranial cavity diminished.

The sphenoidal sinus shows some slight loss of translucency and its floor appears to be thicker than normal. The shape of the pituitary fossa is not abnormal.

The posterior portion of the skull is not involved; the sutures are not obliterated and the vascular grooves show normal appearances. No digital markings are to be seen in any part of the calvarium.

B. The Skull: anterior view (Fig. 7). The skull shows a definite asymmetry. The transverse diameter of the cranium is increased, the right temporo-parietal region showing a distinct bulge. This is possibly compensatory to the diminution in the sagittal diameter.

The frontal bone shows an increase in opacity, more marked on the left side. The obliteration of the frontal sinuses is again seen, but in addition there is now evident a diminution in size of the left orbital cavity, due to encroachment by the thickened bones forming its roof, inner

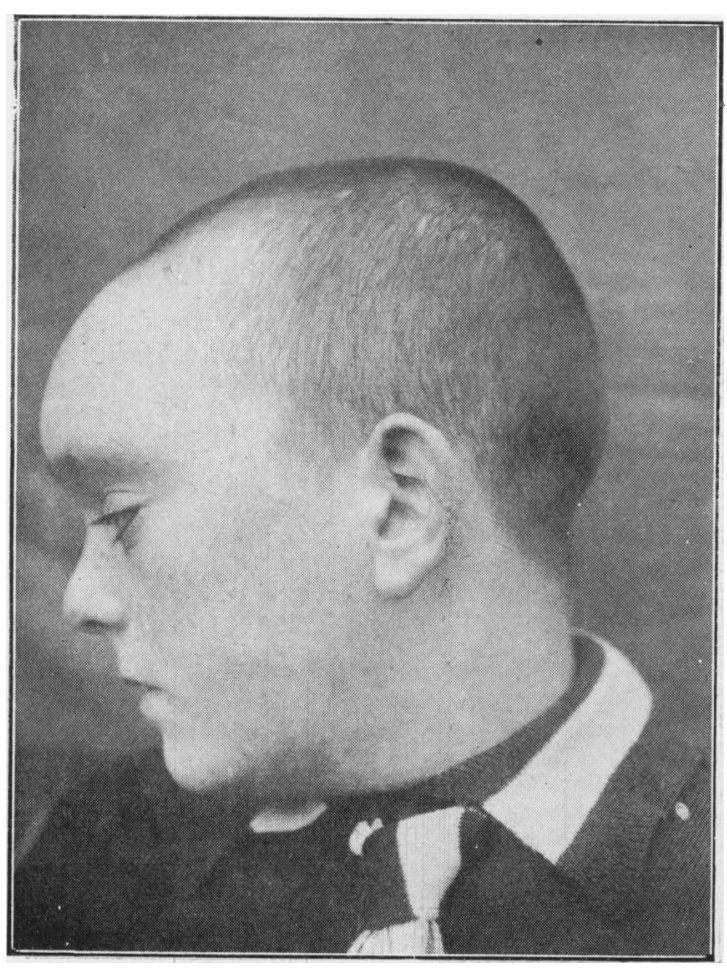

FI(i. 3

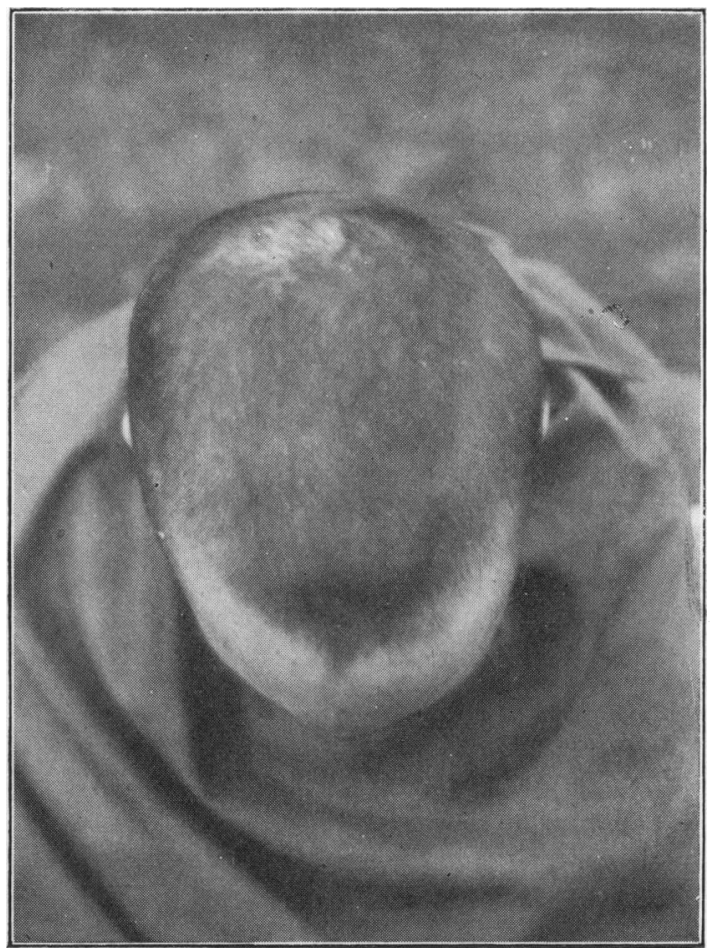

Fic. 4 


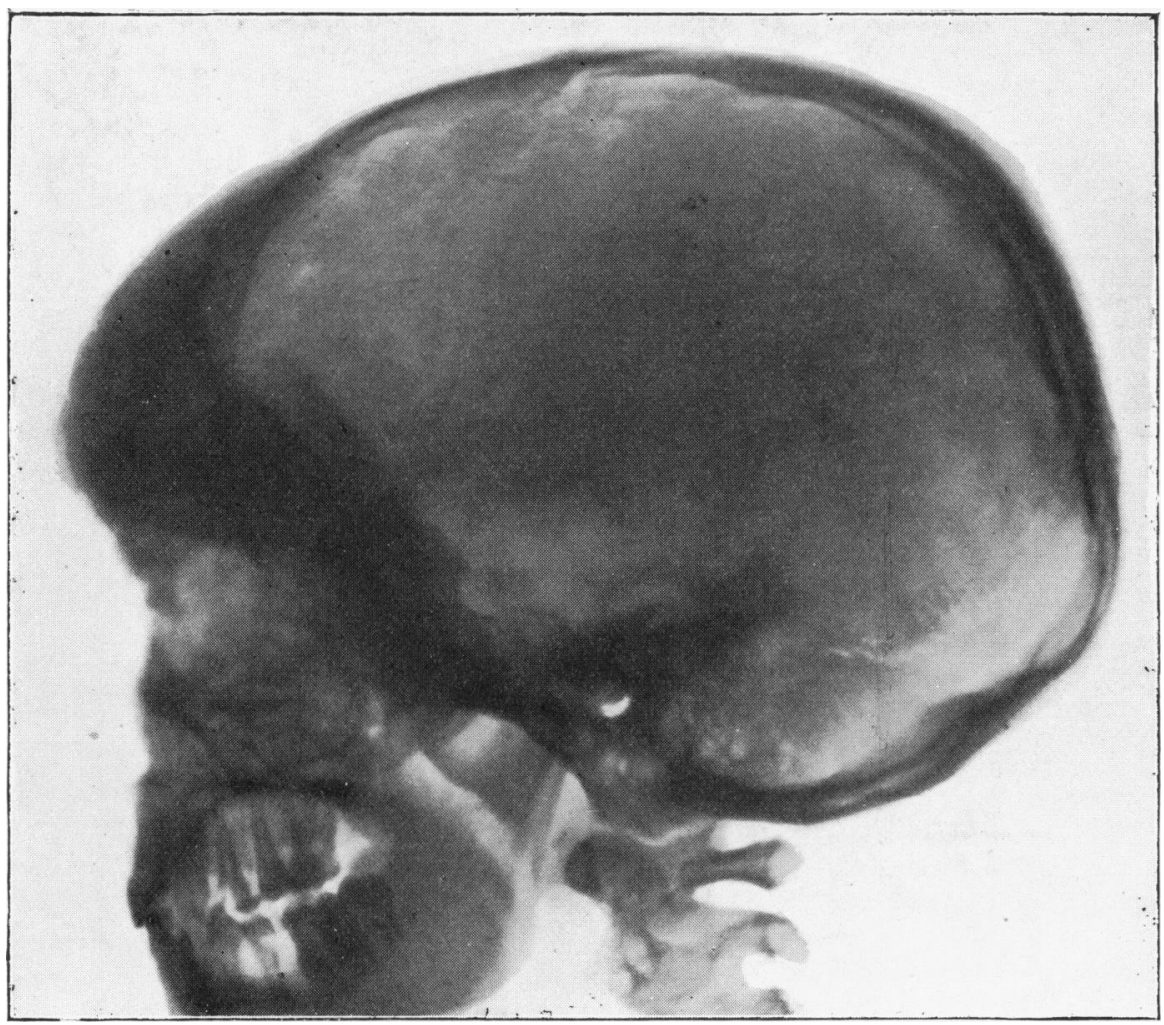

Fig. 5. Skull : Left Lateral, View.

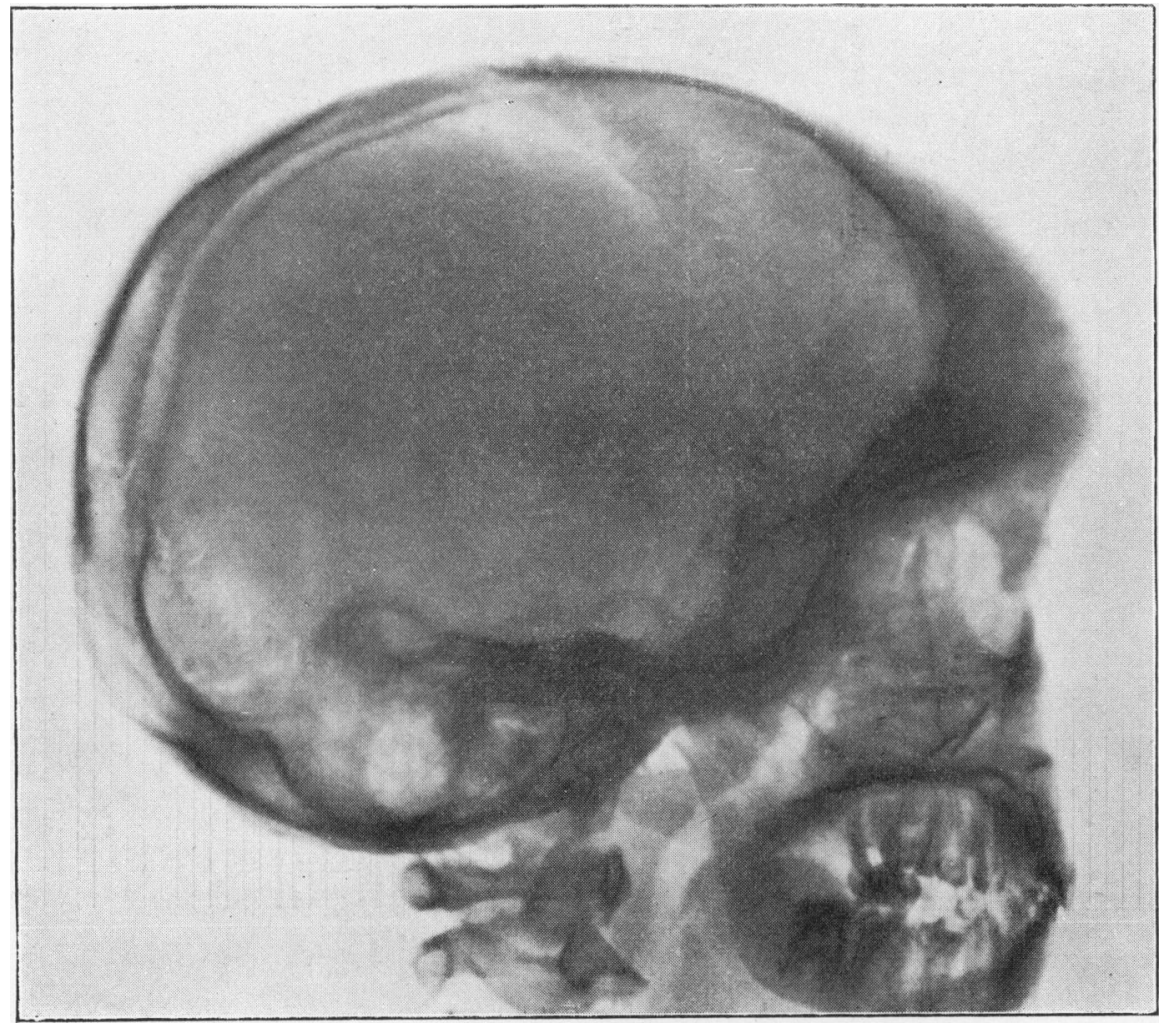

Fig. 6. Skoli : Right lateral View. 


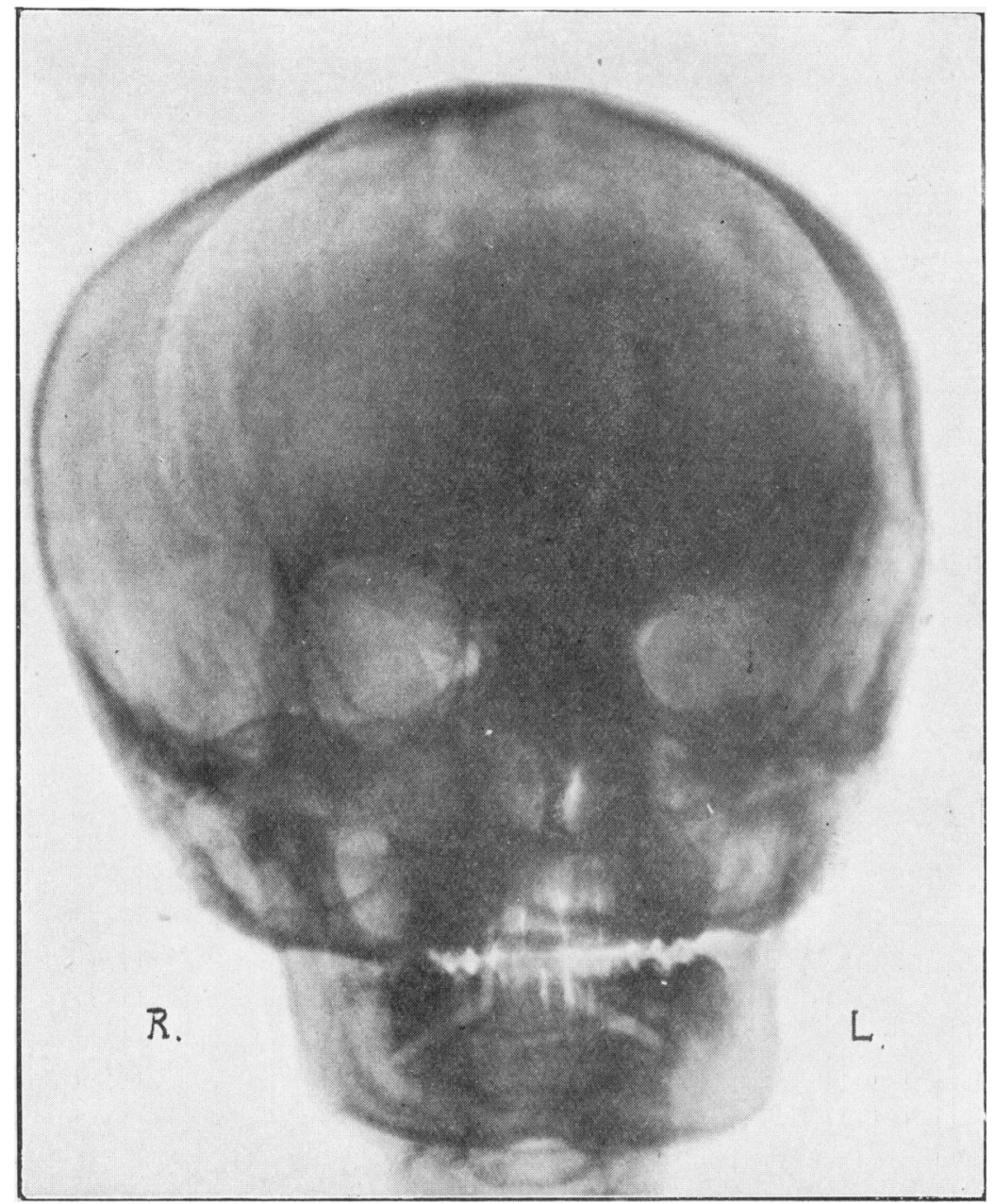

Fin: 7. SkTta: Fack Dow: 
walls and floor. Whilst the ethmoidal cells are visible on the right side, no such cells can be seen on the left side.

The upper part of the left nasal cavity is occluded and the septum displaced to the right. From this it would appear that the ethmoid bone is also involved in the process of bony thickening. The sphenoidal fissure on the left side is on a higher plane than that of the right side.

C. Other bones. All other bones of the entire skeleton are radiographically normal.

2. Report on Ears, Nose and Throat. (Dr. W. Sanderson.)

The left middle turbinate bone is enlarged and cystic in appearance; and there is a small pharyngeal tonsil. Otherwise there is nothing abnormal in the nasal passages or nasopharynx. The tonsils are not septic. Both maxillary antra and both frontal sinuses are dull on transillumination. There is no indication of sepsis in the nasal accessory sinuses. The larynx and ears are normal. There is probably some defect in the sense of smell, but the results obtained (testing both nostrils at once, and also separately) have been too contradictory to be of value.

3. Report on Eyes. (Mr. A. McK. Reid.)

$$
\begin{aligned}
& \text { Right Vision }=\frac{6}{12} \text { with }+3 \cdot 0 \mathrm{D}=\frac{6}{6} \\
& \text { Left Vision }=\frac{6}{12} \text { with } \frac{+4 \cdot 0 \mathrm{D} \text { sph. }}{+0 \cdot 5 \mathrm{D} \text { cyl. axis. } 90^{\circ}}=\frac{6}{6}
\end{aligned}
$$

The media are clear, and the fundi normal. There is no sign of increased intracranial pressure, nor of local pressure on the optic nerves.

The orbital margins are not irregular ; and while the left eye is anterior to the right, this does not appear to be due to a localized thickening of the bone proptosing the eye, but suggests rather that the whole orbit has been pushed forwards en masse. For fields of vision see Fig. 8 .

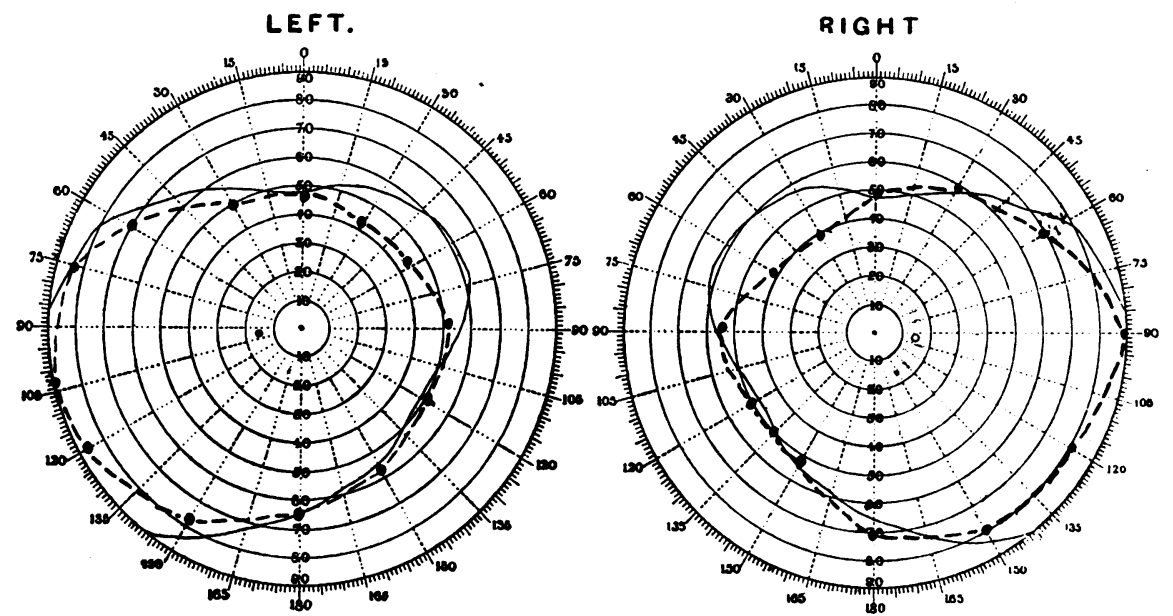

Fig. 8. Outline of the patient's fields of vision for white shown thus :

4. Report on Teeth. (Mr. P. G. Capon.)

The alveoli and teeth are well-formed and appear to be normal. The dental arches are satisfactory (Fig. 9.) Radiograms taken of all teeth do not show any special abnormality of tooth- or bone-structure. 


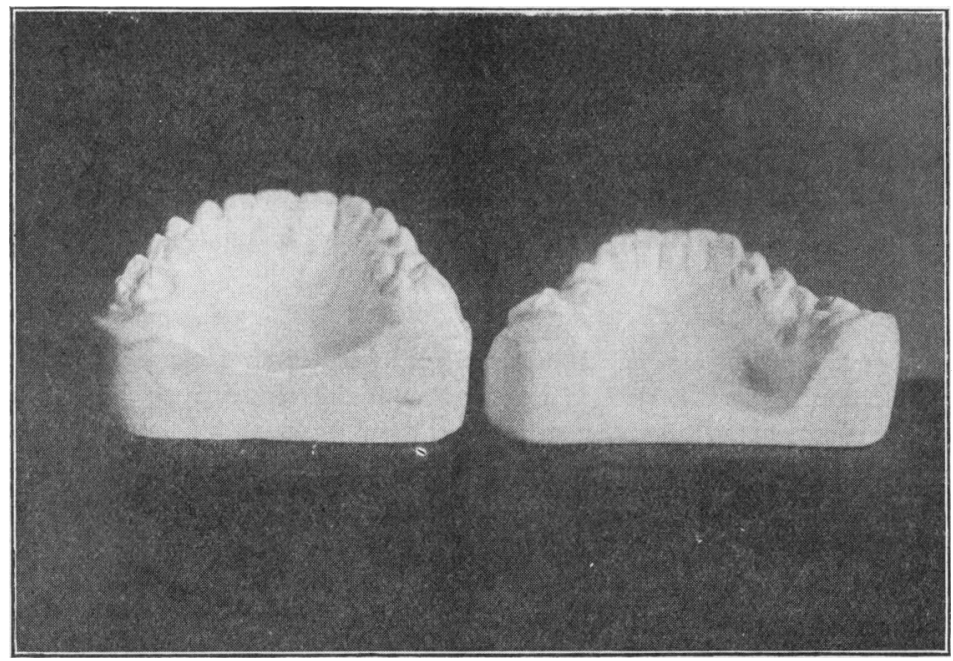

Fic. 9

5. Biochemistry of Blood, Vrine and Cerebro-spinal fluid. (Dr. R. Coope.)

A. Blood. (i) Calcium. $11 \cdot 1 \mathrm{mgrm}$. per $100 \mathrm{c.cm}$.

(ii) Glucose Tolerance Test (using $50 \mathrm{grm}$. of gltcose).

\begin{tabular}{|c|c|c|c|c|c|c|c|c|c|}
\hline \multirow{2}{*}{\multicolumn{4}{|c|}{$\begin{array}{l}\text { Before dose } \quad \ldots \\
\frac{1}{2} \text { hour after dose }\end{array}$}} & \multirow{2}{*}{$\begin{array}{l}\cdots \\
\cdots\end{array}$} & \multirow{2}{*}{$\begin{array}{l}\cdots \\
\cdots\end{array}$} & $\cdots$ & \multicolumn{2}{|c|}{$\begin{array}{l}\text { Ilcod. } \\
66.6 \text { mgrm. } \%\end{array}$} & \multirow{2}{*}{$\begin{array}{l}\text { Urine. } \\
\text { Atsent. } \\
\quad,\end{array}$} \\
\hline & & & & & & $\ldots$ & $80 \cdot 0$ & , & \\
\hline$i$ & , & , & , & $\ldots$ & $\ldots$ & $\ldots$ & $111 \cdot 0$ & , & , \\
\hline $1 \stackrel{1}{1}$ & , & , & , & $\ldots$ & $\ldots$ & $\ldots$ & $100 \cdot 0$ & , & , \\
\hline & , & „, & , & $\ldots$ & $\ldots$ & $\ldots$ & 97.0 & , & ", \\
\hline
\end{tabular}

(iii) Wassermann reaction : negative.

B. Urine. Daily volume witlin normal limits. Reaction acid. Protein, a very slight trace at one examination only. Urobilin, very slight excess. Indoxyl normal. Acetone and sugar absent. Microscopically, nothing of special note.

C. Cerebro-spinal Fluid. Clear, watery fluid, discharged at a rate greater than normal. Protein normal. Sugar, $71 \mathrm{mgrm}$. per $100 \mathrm{c.cm}$. No gold curve obtained. Less than one cell per 1 c.mm. Culture sterile. Wassermann reaction negative in all dilutions.

6. Examination of affected bone.

Mr. J. T. Morrison reflected a small scalp-flap in the right parietal region and removed fragments of superficial bone, which was found to be surprisingly hard, and highly polished. A bone-fragment was incubated in culture-medium ; no growth of micro-organisms was obtained.

Histological examination showed that the spicules of bone consisted only of very dense compact osseous tissue. It is evident that the zone of active pathological change was not reached at operation.

\section{Discussion.}

'The name 'leontiasis ossea' was chosen by Virchow ${ }^{12}$ because the victims of cranial and facial hyperostosis bore some resemblance to patients suffering with fibroma molluscum ('leontiasis'). Obviously a definition of this kind allows too wide a latitude, and it is only natural that many different pathological conditions were regarded as cases of leontiasis ossea. Even Horsley's ${ }^{4}$ classical paper, handicapped by the lack of radiographic examination, leaves the reader uncertain of the pathological nature of the cases so carefully described. 
Before the papers of Lawford Knaggs ${ }^{7}$ were published in 1923 the literature of the subject was most confusing; but the thesis of Ramijean ${ }^{11}$ may be singled out as a careful study containing a very valuable bibliography.

Lawford Knaggs (loc. cit.) gave a full description of the disease ; his papers have re-stimulated interest in its ætiology, pathology, and relationship to other chronic affections of bone, and especially to osteitis deformans (Paget's disease).

Most authors agree that in general terms the histological appearances of leontiasis ossea are those of osteitis fibrosa (osteodystrophia fibrosa) ; in brief, the normal bone disappears and is replaced by poorly calcified osteoid tissue, which undergoes fibrous transformation, with later ossification. (See $\operatorname{Marx}^{\boldsymbol{\theta}}$; Lemaitre, Rouget et Ruppe ${ }^{8}$; Fettu $^{2}$ ).

There is less unanimity regarding the relationship of leontiasis ossea to Paget's disease. Dawson and Struthers ${ }^{1}$ in a very striking paper on general ized osteitis fibrosa hold that the changes seen in leontiasis ossea are consistent with those outlined as the late stages of osteitis deformans ; Marx (loc. cit.) states that leontiasis ossea is like osteitis fibrosa, yet not identical with Paget's disease ; Kanavel ${ }^{5}$, writing in 1907 , stated that the two conditions bore no relationship.

The clinical differences between leontiasis ossea and Paget's disease, such ${ }^{1}$ as age at onset, and distribution of bone-lesions, are generally well marked; but Hamburger and Nachlas ${ }^{3}$ have reported a case which lends support to their view that at all events some examples of leontiasis ossea are the same as Paget's disease.

The ætiology of leontiasis ossea is still unknown.

In its clinical picture the signs and symptoms are largely a question of chance, and depend upon the site of the hyperostosis, and the structures which become compressed by the overgrowth of bone. Morelli ${ }^{20}$ has recently reported two interesting examples showing ophthalmological signs.

In conclusion I wish to express my thanks to Dr. T. J. Coakley who referred the patient to me ; to my colleagues, whose able reports are my justification for publishing this case ; and to Mr. Lawford Knaggs, who has very kindly given me the help of his expert knowledge of this disease.

\section{REFERENCES.}

1. Dawson, J. W. \& Struthers, J. W., Edin. Med. .J., Edin., 1923, n.s. XXX, 421.

2. Fettu, H., Thèse de Paris, Paris, 1924.

3. Hamburger, L. P., \& Nachlas, I. W., Arch. Surg., Chic., 1926, XII, 727.

4. Horsley, V., Practitioner, Lond., 1895, n.s. II, 12.

5. Kanavel, A. B., Surg., Gyn. and Obstet., Chic., 1907, IV, 719.

6. Knaggs, R. L., Inflammatory and Toxic Dis. of Bone, Bristol, 1926.

7. Knaggs, R. L., Brit. J. Surg., Bristol, 1923, XI, 347.

8. Lemaitre, F., Rouget, J. \& Ruppe, C., Arch. Internat. Laryngol., Otol, etc., 1924, III, 903.

9. Marx, H., Ziegler's Beiträge, 1927, LXXVII, 501.

10. Morelli, E., Ann. di Ottalm. e Clin. Ocul., 1925, LIII, 773.

11. Ramijean, R., Thèse de Paris, Paris, 1921.

12. Virchow, R., Die Krankhaften Geschwulste, Berlin, 1864, II, 23. 